\title{
O USO DE IMAGEM DE SATÉLITE NA AVALIAÇÃO DE INDICADORES DE FLORESTA URBANA DA CIDADE DE ARINOS, MG
}

\author{
THE USE OF SATELLITE IMAGE IN THE EVALUATION OF URBAN FOREST \\ INDICATORS FROM THE CITY OF ARINOS, MG
}

\author{
Diorny da Silva Reis ${ }^{1}$, Isadora Mendes da Silva², Demóstenes Ferreira da Silva Filho ${ }^{3}$, \\ Jefferson Lordello Polizel ${ }^{4}$, Carliane de Souza Pires ${ }^{5}$, Gustavo Torquatro Oliva ${ }^{6}$
}

\section{RESUMO}

Pesquisas relacionadas à Florestas Urbanas tem sido utilizadas como ferramentas para o planejamento e gestão do espaço público. Um dos instrumentos para realização desses estudos é a utilização de imagens de satélite. A presente pesquisa avaliou o uso de imagem multiespectral pancromática do satélite Quickbird para a obtenção de indicadores de floresta urbana da cidade Arinos-MG. Foram feitas classificações supervisionadas para caracterização de alvos intra-urbanos e as proporções estudadas para a mensuração da floresta urbana utilizando-se indicadores compostos que consideraram a proporção entre espaço arborizado e espaço impermeabilizado, a proporção entre espaço arborizado e espaço construído, além da obtenção do Índice de Floresta Urbana. Os indicadores obtidos para a área estudada mostraramse satisfatórios quando comparados aos encontrados em outros trabalhos. Além disso, os dados sugerem que há um grande potencial de incremento da arborização urbana, uma vez que esta área apresentou um Espaço Livre Herbáceo em torno de $50 \%$. Concluiu-se que as imagens multiespectrais de satélite são indicadas na obtenção de dados para a análise da Floresta Urbana, podendo ser usados para reconhecimento da Qualidade da distribuição da vegetação no espaço urbano e suas relações com os demais componentes das cidades.

Palavras-chave: Classificação supervisionada; Sensoriamento remoto; Cobertura arbórea.

\section{ABSTRACT}

Researches related to Urban Forests have been used as tools for planning and management of public space. One of the instruments for these studies is the use of satellite images. The present study evaluated the use of the panchromatic multispectral image of the Quickbird satellite to obtain urban forest indicators from the city of Arinos-MG. Supervised classifications were used to characterize intra-urban targets and the proportions studied for the measurement of urban forest using composite indicators that considered the proportion between wooded space and waterproofed space, the proportion between wooded space and built space, besides obtaining the Urban Forest Index. The indicators obtained for the studied area were satisfactory when compared to those found in other studies. In addition, the data suggest that there is a great potential to increase urban afforestation, since this area presented a Herbaceous Free Space around $50 \%$. It is concluded that the multispectral satellite images are indicated in the data collection for the analysis of the Urban Forest, and can be used to recognize Quality of vegetation distribution in urban space and its relations with other components of cities.

Keywords: Supervised classification; Remote sensing; Tree cover.

Recebido em 02.11.2016 e aceito em 10.04.2017

1 Gestor Ambiental, Mestre, Professor do IEMA - Buriticupu/MA. - dreis80@yahoo.com.br

2 Bióloga. Mestra em Ciências, opção Conservação de Ecossistemas Florestais, pelo Programa de Pós-Graduação em Recursos Florestais da ESALQ da Universidade de São Paulo - Piracicaba/SP - isadoramendes154@gmail.com

3 Engenheiro Agrônomo, Doutor, Professor do Departamento de Ciências Florestais na Escola Superior de Agricultura Luiz de Queiroz da Universidade de São Paulo - Piracicaba/SP - dfilho@usp.br

4 Analista de Sistemas, Doutor em Geografia Física pela Faculdade de Filosofia, Letras e Ciências Humanas da Universidade de São Paulo - Piracicaba/SP - jlpolize@usp.br

5 Tecnóloga em Gestão Ambiental, pelo IF do Norte de Minas Gerais - Arinos/MG - carlianearinos@gmail.com

6 Gestor Ambiental e Mestre em Ciências pelo Programa de Pós-Graduação em Recursos Florestais da Escola Superior de Agricultura Luiz de Queiroz da Universidade de São Paulo - Piracicaba/SP - gustavo.oliva@usp.br 


\section{INTRODUÇÃO}

A vegetação urbana, quando corretamente implantada, desempenha um conjunto importante de funções responsáveis pela melhoria da ambiência urbana, podendo minimizar o impacto ambiental causado pelos efeitos antrópicos da expansão das cidades, resultando em maior conforto para a população (PIRES, 2010).

A criação e a manutenção de áreas verdes urbanas são sempre defendidas pela sua capacidade de proporcionar à população uma melhor condição ambiental. Essas áreas onde existe predomínio do "verde" exercem papel positivo na qualidade de vida das pessoas, devido às suas funções sociais, ecológicas, estéticas e educativas, agindo como fator amenizador das condições negativas da urbanização (BARGOS; MATIAS, 2011; RIBEIRO et al., 2013; MARTINI et al., 2014). Costa et al. (2012), sustenta que a presença de áreas verdes nas cidades traz inúmeras melhorias à qualidade de vida do cidadão, exercendo funções estéticas, de lazer e educacional.

O espaço urbano é constituído basicamente por espaços construídos - áreas edificadas compostas por casas, comércio e indústrias, áreas destinadas à circulação da população tais como o sistema rodoferroviário, e áreas não edificadas, definidas como "espaços livres de construção" (COLTRO; MIRANDA, 2007).

É importante equacionar de maneira sistêmica a proporção entre o total de vegetação arbórea e os espaços livres permeáveis e construídos de modo a atender as necessidades da população residente, tanto com relação a quantidade de árvores existentes, quanto com relação à sua distribuição nos espaços públicos e particulares.

Silva Filho et al. (2005), afirmam que no Brasil, algumas cidades possuem levantamentos sobre as condições e disponibilidade de áreas verdes e arborização urbanas. Segundo os autores, na maioria das vezes esses dados são obtidos, por amostragem e referem-se somente ao tema pesquisado, áreas verdes ou arborização, sem confrontações amplas e desejáveis com as demais estruturas e elementos constituintes da área urbana como edificações, tipos de pavimento, solo e demais elementos.

O emprego de geotecnologias, como o sensoriamento remoto, apresenta uma economia de tempo e recursos e tem se tornado cada vez mais comum no estudo do uso e cobertura do solo urbano, pois apresenta entre suas vantagens além do relativo baixo custo, a disponibilidade e facilidade na aquisição de dados fornecidos pelos sensores remotos de maneira confiável em curto espaço de tempo (POLIZEL, 2009; SILVA, 2012).

Silva Filho et al. (2005), testou e confirmou a eficácia do uso de imagens aéreas de alta resolução na obtenção de indicadores para definição de prioridades de intervenção na ampliação da cobertura arbórea urbana. 
Londe e Mendes (2014), destacam que a responsabilidade de planejar, criar e gerir esses espaços de singular importância para o bem-estar social é do poder municipal, sendo que a gestão e o planejamento das áreas verdes urbanas devem estar previstas no Plano Diretor. Segundo os autores um dos problemas encontrados nos planos é a falta de concisão e objetividade, já que apresenta conceitos muito abrangentes de área verde, os quais, geralmente, englobam praças, jardins, unidades de conservação, canteiros centrais de ruas e avenidas, trevos e rotatórias de vias públicas.

Além disso, o conceito teórico do termo "área verde" ainda é uma questão controversa, pois a definição de quais espaços são realmente considerados áreas verdes geram dificuldades de compreensão dessa temática. Assim, a falta de concordância conceitual causa uma série de conflitos sobre o processo de avaliação da vegetação dos municípios, prejudicando a comparação entre as pesquisas realizadas (COSTA; COLESANTI, 2011; BARGOS; MATIAS, 2011).

Entre os indicadores de Floresta Urbana, temos o Índice de Área Verde (IAV) que é aquele que expressa a quantidade de espaços livres de uso público, em $\mathrm{km}^{2}$ ou $\mathrm{m}^{2}$, pela quantidade de habitantes que vivem em uma determinada cidade. Então, neste cômputo, entram as praças, os parques e os cemitérios, ou seja, aqueles espaços cujo acesso da população é livre (DUARTE; ZIANTONIO-FILHO, 2010).

Outro índice que pode ser gerado é o índice de cobertura vegetal em área urbana. Para obtenção desse índice é necessário o mapeamento de toda cobertura vegetal de um bairro ou cidade e posteriormente quantificado em $\mathrm{m}^{2}$ ou $\mathrm{km}^{2}$. Conhecendo-se a área total estudada, também em $\mathrm{m}^{2}$ ou km², chega-se posteriormente à porcentagem de cobertura vegetal que existe naquele bairro ou cidade. Se mapearmos somente as árvores, então esse índice expressará somente a cobertura vegetal de porte arbóreo ((DUARTE; ZIANTONIO-FILHO, 2010; LUCON; PRADO-FILHO; SOBREIRA, 2013).

Reis (2014), em sua dissertação de mestrado, demostrou que áreas com maior Índice de Cobertura Vegetal, pode apresentar uma diferença de até $3^{\circ} \mathrm{C}$ na temperatura, concluindo que um aumento deste índice além de determinar uma maior estabilidade térmica e consequente melhoria no conforto térmico, fornece uma melhor percepção da qualidade ambiental pelos usuários dessas áreas.

Silva (2012), também em sua pesquisa de mestrado, demonstrou que os valores mínimos de temperatura e máximos de umidade localizaram-se mais próximos às áreas altamente arborizadas e que o vento é determinante do direcionamento do "frescor". Algumas coberturas, principalmente asfalto e copa de árvore, possuem correlação na variação da umidade e da temperatura dos pontos estudados sendo determinantes na questão do conforto térmico em espaços abertos. 
De acordo com todos os benefícios que a vegetação pode trazer ao ser humano, conclui-se que em lugares sem ou com baixa quantidade de vegetação (abaixo de $5 \%$ ) a qualidade ambiental é bem inferior à desejável (NUCCI, 1996).

Silva Filho et al. (2005), avaliaram a qualidade do desenho urbano e da floresta urbana por meio de dados das imagens de videografia aérea multiespectral em nove bairros da cidade de Piracicaba -SP, onde foram propostos indicadores compostos entre os quais a proporção entre espaço arborizado sobre espaço impermeabilizado e a proporção entre espaço arborizado sobre espaço construído. Este estudo concluiu ser recomendável a utilização desses indicadores para avaliação da floresta urbana.

Shans, Giacomeli e Sucomine (2009), destacam que apesar de muitos trabalhos demonstrarem a importância das árvores urbanas, não se pode perceber uma atenção focada para este assunto nas políticas públicas dos centros urbanos, pois apesar de sua grande relevância, poucas cidades brasileiras possuem um planejamento efetivo para arborização de suas vias e espaços públicos, mesmo porque o Brasil carece de uma política nacional específica para o referido setor, que venha estabelecer diretrizes norteadoras para sua gestão, perdendose assim sua eficácia. De modo essencial faz-se necessário uma ação mais efetiva por parte do poder público no que se refere à arborização dos espaços públicos analisados na cidade. Cabe a população conhecer a importância da arborização urbana e exigir a criação de políticas específicas de planejamento criterioso e manutenção (LIMA NETO; SOUZA, 2009).

Considerando as Florestas Urbanas como um complexo de extrema importância e que propicia uma melhoria na qualidade socioambiental de uma cidade, o objetivo desta pesquisa foi utilizar imagem multiespectral de satélite para identificar e quantificar a arborização urbana da cidade de Arinos - MG, e por meio dos dados espaciais de uso e cobertura do solo obtidos, calcular e avaliar seus Indicadores de Floresta Urbana (IFU).

\section{MATERIAL E MÉTODOS}

\section{Área de estudo}

O estudo foi realizado no município de Arinos, localizado no interior de Minas Gerais, à aproximadamente $654 \mathrm{~km}$ da capital Belo Horizonte e a $265 \mathrm{~km}$ da capital federal. Tem seu marco zero na Latitude: $15^{\circ} 55^{\prime}$ 01" S e Longitude: 460ㅜ $20^{\prime \prime}$ W. A estimativa de sua população segundo o censo do Instituto Brasileiro de Geografia e Estatística de 2010 é de 17.674 habitantes, sendo que cerca de 60\% (10.854 habitantes) vive na zona urbana correspondente a área de estudo. Seu bioma predominante é o cerrado. 


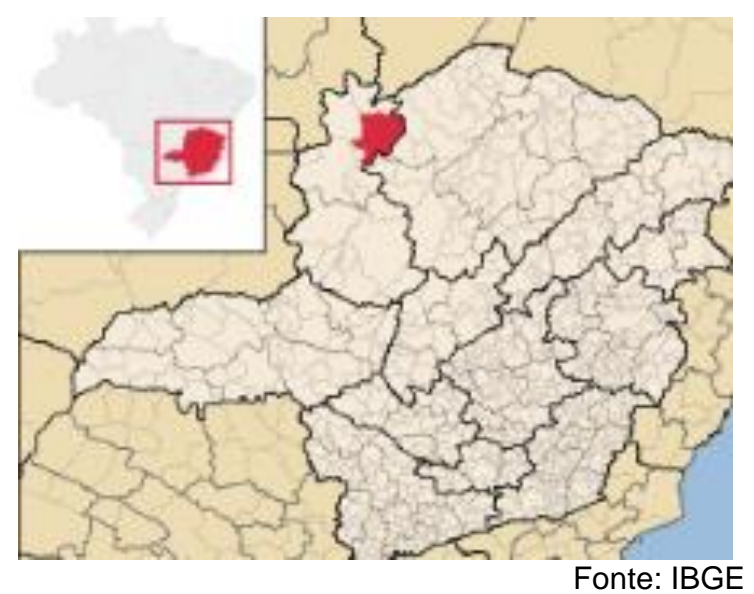

Figura 1. Localização geográfica o município e Arinos-MG

Figure 1. Geographical location of the municipality of Arinos-MG

\section{Métodos de amostragem}

A imagem em cena única, foi obtida pelo satélite Quickbird com resolução de $60 \mathrm{~cm}$ banda pancromática e 2,4m banda multiespectral (vermelho, verde, azul e infravermelho próximo). A resolução espacial é de 96 dpi, e as dimensões são de 844 x 546 pixels. Por se tratar de imagem de alta resolução espectral e não espacial, sua escala de aplicação é de 1:50.000 com erro aproximado de $25 \mathrm{~m}$.

$\mathrm{Na}$ Figura 2, encontram-se a imagem multiespectral de alta resolução de alvo interurbano da cidade de Arinos-MG, com recorte correspondente a malha urbana. Houve a necessidade de recorte na imagem para que a área circundante não interferisse no cálculo do dos Índices de Floresta Urbana, possibilitando, portanto, uma maior proximidade com a realidade vivenciada pela população residente.

A

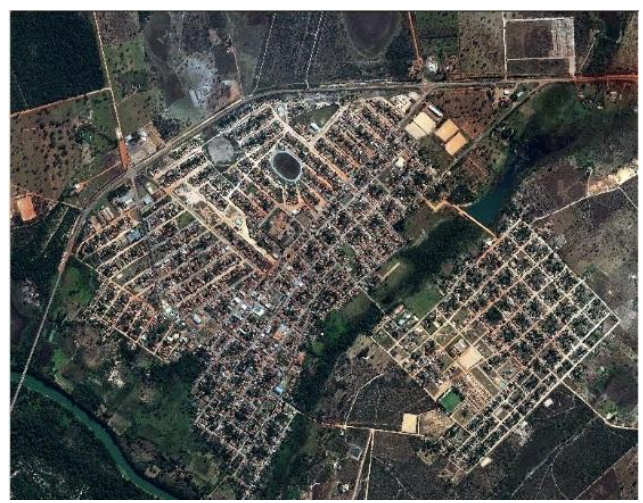

B

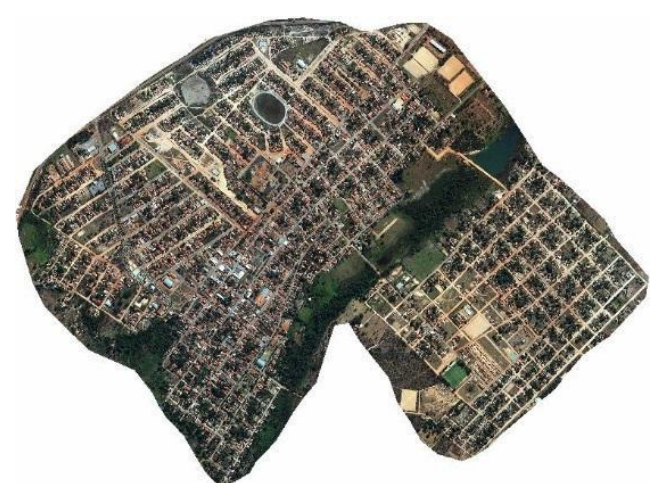

Figura 2. Imagens aéreas multiespectrais de alta resolução de alvo intra-urbanos correspondentes à unidade amostral 1 (A) e imagem de satélite da cidade de Arinos e 1 (B) recorte da área experimental

Figure 2. Multispectral aerial images of high resolution intra-urban target corresponding to the sampling unit 1 (A) satellite image of the city of Arinos and 1 (B) clipping of experimental area 


\section{Classificação supervisionada}

A coleta de dados espaciais de alvos intra-urbanos na cidade de Arinos, foi obtida por meio de uma imagem multiespectral do satélite Quickbird. Os dados qualitativo e quantitativo da variável de interesse (cobertura arbórea) e demais uso e ocupação do solo foram analisados no software MultiSpec@ versão 3.3, segundo metodologia descrita em Reis (2014). O método de classificação utilizado foi o de pixel a pixel de células homogêneas com média de 157 pixels por campo mesclado. O classificador utilizado foi o $\mathrm{ECHO}$, e o algoritmo o Maximum Likelihood com níveis de probabilidade de $91 \%$.

Para a identificação, quantificação e qualificação das estruturas urbanas presentes na área de estudo, foi utilizado o método de classificação supervisionada, com a finalidade de analisar a imagem digital, categorizando cada um de seus pixels em classes de cobertura do solo por meio de algoritmos baseados em método estatísticos, para, por fim, obter um mapa temático com a representação e distribuição espacial dessas classes. Para a presente pesquisa foram definidas sete classes, sendo elas, copa de árvore, gramínea, solo exposto, asfalto, sombra, vereda e telha cerâmica.

\section{Validação estatística}

Para averiguação da exatidão dos mapeamentos temáticos, foram confeccionadas matrizes de erro, dendrogramas por distância euclidiana e foi usado o índice de precisão Kappa (LANDIS; KOCH, 1977). Em sensoriamento remoto é comum o uso da estatística Kappa para avaliar a concordância entre a verdade terrestre e o mapa temático. O coeficiente kappa é uma medida de concordância estatística na forma de uma matriz de confusão que é obtida após a verificação dos resultados obtidos na classificação digital (LU; WENG, 2006)

A interpretação do resultado seguiu a escala feita por Landis e Koch (1977), conforme se encontra na tabela 1.

Tabela 1. Valores de referência do índice Kappa de acordo com a qualidade do mapeamento Table 1. Kappa index reference values according to the quality of the mapping

\begin{tabular}{c|c}
\hline Valor do Kappa & Qualidade do mapeamento \\
\hline $0 \%-20 \%$ & Pobre \\
$21 \%-40 \%$ & Leve \\
$41 \%-60 \%$ & Médio \\
$61 \%-80 \%$ & Moderado \\
$81 \%-100 \%$ & Boa/ substancial \\
\hline
\end{tabular}

Fonte: Adaptado de Reis (2014) 
O software MultiSpec (c permite por meio da construção de uma matriz de erro utilizarse de técnicas de análise multivariada para determinar a concordância da classificação (classificação temática) com a verdade de campo. Para a validação estatística da exatidão da classificação supervisionada das áreas de estudo, utilizou-se o índice Kappa, obtido pelo mesmo software da classificação supervisionada, o programa MultiSpec@, que de acordo com o recomendado por Landis e Koch (1977), apresentaram a qualidade de mapeamento considerada ótima (entre $81 \%$ e $100 \%$ ) conforme mostrado na tabela 1.

\section{Indicadores de floresta urbana}

Silva Filho et al. (2005), propôs os índices abaixo para composição das variáveis obtidas das imagens de satélite:

$$
P A I=\frac{E L A}{(E L A+E L I)}
$$

Em que: $\mathrm{PAI}=$ Proporção de Espaço Livre Arborizado; ELA = Espaço Livre Arborizado e ELI= Espaço Livre Impermeável. O PAI pode variar de 0 a 1, sendo 1 o máximo desempenho de uma área neste índice.

$$
P A C=\frac{E L A}{(E L A+E C)}
$$

Em que: $P A C=$ Proporção de Espaço Livre Arborizado; ELA = Espaço Livre Arborizado e EC = Espaço Construído. Assim como o PAI, o PAC pode variar de 0 a 1, sendo 1 o máximo desempenho de uma área neste índice.

$$
P A V=\frac{E L A}{(E L A+E L H)}
$$

Em que: PAV = Proporção de Espaço Livre Arborizado em relação ao Espaço Livre Herbáceo (ELH), caracterizando o Espaço Livre Vegetado, que é a soma de toda a cobertura vegetal.

$$
\mathrm{IFU}=\mathrm{PAI}+\mathrm{PAC}
$$

Em que: IFU = Índice de Floresta Urbana. O IFU pode variar entre 0 e 2, sendo 2 o máximo desempenho para este índice.

Nucci (1996), em sua tese de doutorado, propôs o Índice de Verde por Habitante. Este índice consiste na obtenção de áreas vegetadas em $\mathrm{m}^{2}$, dividido pela população residente na área correspondente. Considerando todo o verde existente tanto em áreas públicas, quanto em 
áreas particulares. Silva, Santos e Oliveira (2016), consideraram o índice de cobertura vegetal, como sendo a somatória das áreas de copa de árvore dividido pela população residente.

\section{RESULTADOS E DISCUSSÃO}

Os resultados obtidos com a classificação supervisionada são apresentados na figura 4. Foi gerado um mapa temático referente à área amostral, representado na figura 3. $O$ índice Kappa encontrado demonstra que a precisão da classificação realizada representa uma boa aproximação com a realidade, sendo este de $97,6 \%$ para a referida malha urbana.

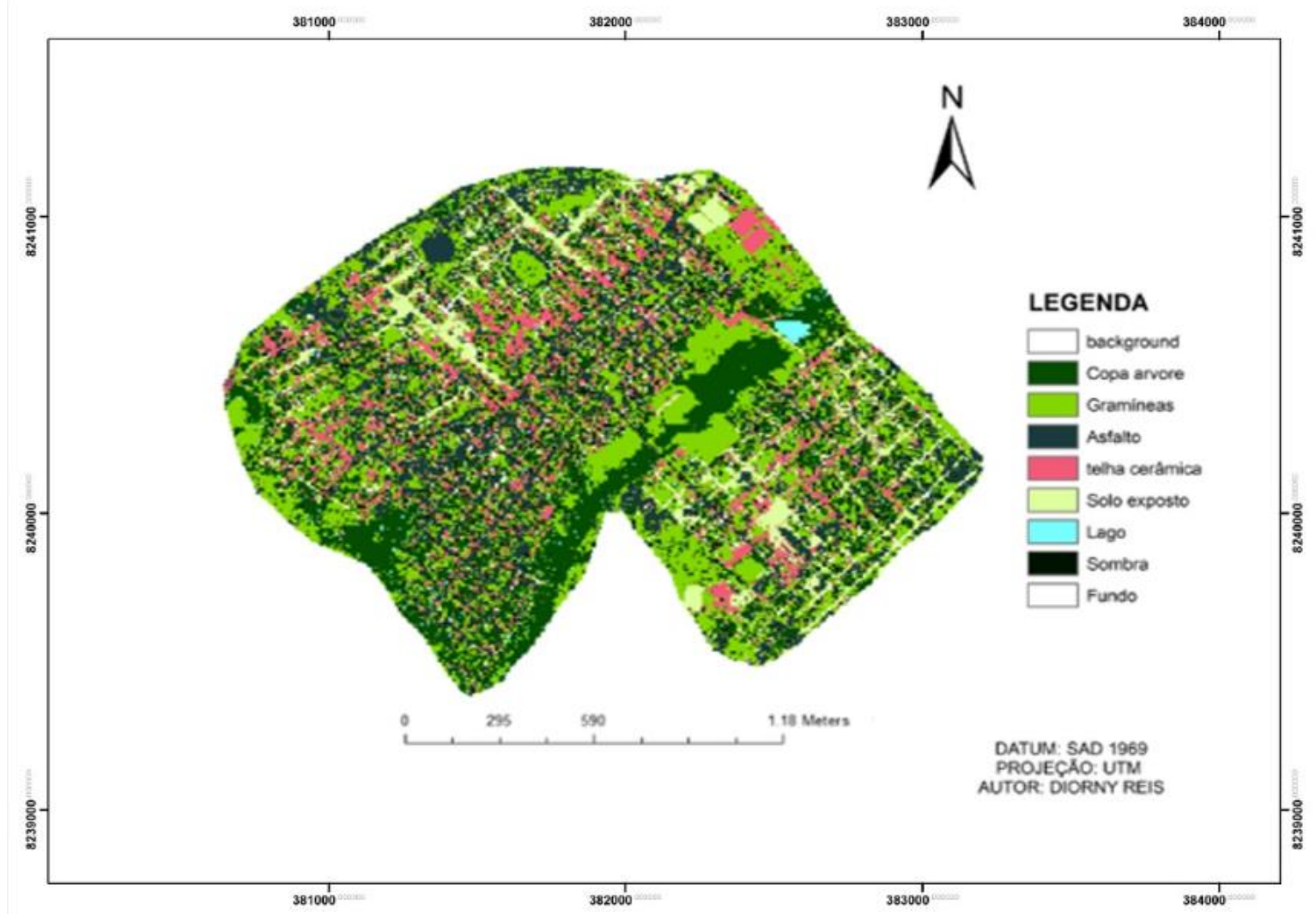

Figura 3. Mapa temático obtido da classificação supervisionada da malha urbana de Arinos-MG Figure 3. Thematic map obtained from supervised classification of urban grid of Arinos-MG 


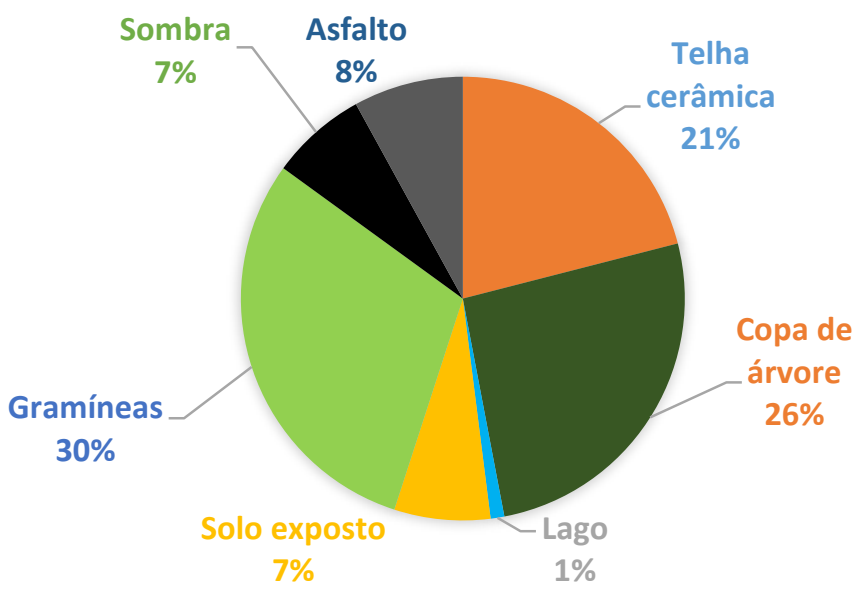

Figura 4. Distribuição por classes de uso do solo no município de Arinos-MG Figure 4. Distribution of land use classes in the city of Arinos-MG

Pode-se observar que a área predominante da paisagem refere-se à gramínea (29\%) seguida da classe copa de árvore (26\%), juntas, estas duas classes constituem a área vegetada total, representando, portanto, $55 \%$ da superfícies da área estudada.

\section{Indicadores de floresta urbana}

De modo a estabelecer um padrão de referência para o aprofundamento da análise dos Indicadores de Floresta Urbana e avaliar condição da qualidade ambiental proporcionada por esses indicadores, foi feito nesta seção, uma comparação entre os resultados obtidos neste trabalho e os resultados obtidos em estudo semelhante realizado por Silva Filho et al. (2005), que teve por objetivo avaliar a qualidade do desenho urbano e da floresta urbana por meio de dados das imagens de videografia aérea multiespectral, em nove bairros da cidade de Piracicaba, SP.

Foi observado que entre dos bairros estudados por Silva Filho et al. (2008), o bairro onde houve as maiores aproximações numéricas entre os indicadores analisados foi o bairro Clube de Campo conforme demonstrado na Tabela 2.

As classes de uso e cobertura do solo foram agrupadas em quatro subclasses para a obtenção do Índice de Floresta Urbana (IFU), sendo essas, o Espaço Livre Arborizado (ELA), o Espaço Livre impermeabilizado (ELI), o Espaço Construído (EC) e o Espaço Livre Herbáceo (ELH) (Tabela 2). 
Tabela 2. ELV - Espaço Livre Vegetado (Herbáceo + Arborizado); PAC - Proporção de árvore por espaço Construído; PAI - Proporção de árvore por Espaço Livre Impermeável; PAV - Proporção de arvore por Espaço Livre Vegetado; IFU - Índice de Floresta

Table 2. ELV - Vegetated Free Space (Herbaceous + Wooded); PAC - Proportion of tree by built space;

PAI - Tree Proportion by Impermeable Free Space; PAV - Tree Proportion by Vegetated Free Space; IFU - Forest Index

\begin{tabular}{c|c|c}
\hline Área & Arinos - MG (\%) & Clube de Campo Piracicaba - SP (\%) \\
\hline Espaço Livre Arborizado & 19,6 & 25,6 \\
\hline Espaço Livre Impermeabilizado & 5,4 & 12,5 \\
\hline Espaço Construído & 25 & 32,3 \\
\hline Espaço Livre Herbáceo & 50 & 14,6 \\
\hline Total Espaço Livre Vegetado & 69,6 & 40,2 \\
\hline PAI $^{*}$ & 0,79 & 0,67 \\
\hline PAC $^{*}$ & 0,44 & 0,44 \\
\hline PAV $^{*}$ & 0,39 & 0,64 \\
\hline IFU* $^{*}$ & 1,23 & 1,113
\end{tabular}

O ELA, que é a somatória de todas as áreas de copa de árvores e arbustos detectadas na videografia da área imageada, em Piracicaba variou entre $25,57 \%$ no bairro Clube de Campo e 6,33\% no bairro São Dimas. No estudo realizado na cidade de Arinos o valor para o ELA foi de 19,6 \%, valor bem próximo do obtido para o Clube de Campo em Piracicaba, revelando um percentual de cobertura arbórea bastante satisfatório, uma vez que, ao contrário da área estudada em Piracicaba que tem característica de parque, considera todo o perímetro da malha urbana da cidade.

Em Piracicaba, o Clube de Campo também apresentou o maior Espaço Livre Herbáceo $(14,6 \%)$ contrastando com o bairro Centro que apresentou 0,0 \% de ELH. Assim, o Clube de campo somou um Espaço Livre Vegetado (ELV) de 40,17 \%, mais uma vez, contrastando com outros bairros onde o ELV variou entre 9,87 \% e 26,5\%. O Espaço Livre Herbáceo (ELH) é o somatório de todos os espaços com grama e outras herbáceas quantificados pela imagem. $\mathrm{Na}$ cidade de Arinos-MG, o ELH é predominante na paisagem com uma ocupação de $50 \%$ da área total imageada, o que é extremamente positivo para o incremento da Floresta Urbana, uma vez que, perfaz um espaço naturalmente potencial para o plantio de árvores. Se considerarmos o Espaço Livre Vegetado (que é a soma do ELH e o ELA) o resultado é ainda mais significativo, onde Arinos apresenta ELV de 69,6\%.

Para o indicador de Espaço Construído (EC), o Clube de Campo apresentou o segundo menor valor, com 32,26\%. Neste mesmo indicador o Centro apresentou 51,89\%, sendo o maior EC o do bairro São Dimas com 62,56\%. Em Arinos, o Espaço Construído (EC), representou 25\% da área estudada. O EC é a somatória de todas as coberturas encontradas na imagem de satélite e quantifica o espaço construído, ou seja, o espaço fechado ou não livre. Tais estruturas urbanas não podem ser ocupadas com vegetação, portanto o EC é um fator negativo na avaliação de 
áreas potenciais para o incremento da arborização urbana, ou criação de espaços de lazer ao ar livre como parques ou praças, por exemplo, o que significa que quanto menor o EC, maior o potencial de incremento da Floresta Urbana.

A área de estudo em Arinos apresentou 5,4\% de Espaço Livre Impermeabilizado (ELI). O ELI refere-se a totalidade de espaços não construídos, ou seja, livres, contudo impermeabilizados por concreto, asfalto ou outro material. O valor apresentado é relativamente baixo, considerando os outros tipos de superfície presentes na imagem, o que é positivo do ponto de vista da qualidade ambiental, uma vez que, essa variável mostra a quantidade de espaço não coberto por árvores e que contribui para o aumento do escoamento superficial da água de chuva na cidade. Para o estudo realizado em Piracicaba, o ELI apresentou o segundo menor valor entre os bairros estudados com um ELI de 12,53\%.

Uma maneira de incrementar a arborização é ampliando a cobertura arbórea em áreas verdes, tanto públicas quanto privadas, neste aspecto a cidade de Arinos, dispõe de considerável espaço potencial e possibilidades de intervenção para o incremento de sua arborização Urbana, onde o ELH (50\%) que é bastante elevado, migraria gradativamente para um maior ELA que atualmente é de $19,6 \%$.

O PAI, que representa a proporção entre o Espaço Livre Arborizado e Espaço livre Impermeabilizado, teve como índice 0,79 . Para esse índice que varia de 0 a 1 , quanto mais próximo de 1 melhor o desempenho da área (SILVA FILHO et al, 2005). Assim, 0,79, pode ser considerado bastante significativo para a malha urbana da cidade de Arinos. Em Piracicaba, a área correspondente ao Clube de Campo por exemplo, apresentou um PAI de 0,67, sendo este valor o de melhor desempenho entre os bairros estudados.

Assim como para o PAI, o PAC, que representa a proporção entre área arborizada e área construída, varia de 0 a 1 . Este indicador apresenta o equilíbrio entre áreas verdes e espaços construídos, sendo que quanto mais próximo de 1, melhor o desempenho. Para este índice a área estudada em Arinos apresentou um PAC de 0,44. Em Piracicaba o PAC variou entre 0,09 para o bairro São Dimas e 0,44 para o Clube de Campo, exatamente o mesmo PAC obtido na cidade de Arinos.

A malha urbana da cidade de Arinos apresentou um PAV de 0,39. O PAV representa a proporção entre Espaço Livre arborizado (ELA) e Espaço Livre Herbáceo (ELH), sendo o máximo de desempenho neste índice também será expresso pelo valor 1. Quando o índice for próximo de 1 indicará que os espaços de cobertura vegetal já estão tomados por árvores e arbustos, não havendo mais espaços livres herbáceos para serem ocupados por árvores.

Desta forma, embora a área estudada em Arinos não apresente um PAV tão elevado, este índice deixa claro o potencial dessa mesma área para o plantio de novas árvores, o que expressa o potencial de incremento de sua Floresta Urbana. Conforme Silva Filho et al, 2005, na 
cidade de Piracicaba, o PAV para o centro da cidade, por exemplo, apresentou um índice ou valor igual a 1,00, ou seja, inexistência de espaço livre para incremento da arborização urbana, por outro lado, o Clube de Campo, apresentou um PAV de 0,64, sendo este o melhor índice entre os bairros estudados.

O Índice de Floresta Urbana pode variar em valores entre 0 e 2, sendo 2 o desempenho máximo para este índice. É um indicador para valorização de espaços arborizados relacionados com os outros constituintes do meio, tais como: ruas, calçadas, quadras, casas e edifícios. Todos esses elementos urbanos estão presentes para a quantificação do desempenho das árvores em "tratar" a cidade, melhorando as condições ambientais para a vida. (SILVA FILHO et al., 2005).

No estudo realizado em Piracicaba, o Clube de Campo apresentou o melhor desempenho para este índice $(1,11)$, enquanto o bairro Centro apresentou o menor desempenho entre os bairros estudados com um IFU de 0,481. Conforme destaca Silva Filho et al. (2005), o Clube de Campo destaca-se positivamente por apresentar índices próximos ao preconizado em literatura que é de $30 \%$ de cobertura herbácea, arbustiva e arbórea. Segundo os autores esta taxa se reflete, em última análise, na proporção indicada para que se obtenham adequadas condições climáticas e de qualidade de vida.

O Índice de Floresta Urbana (IFU), para a área estudada na cidade de Arinos foi de 1,23, superior, portanto, ao bairro Clube de Campo, desta forma pode-se dizer que o resultado é satisfatório e a floresta urbana da cidade de Arinos cumpre seu papel ambiental em prover melhores condições climáticas e qualidade de vida à população residente.

Silva Filho et al. (2005) observou uma tendência nas relações de densidade populacional e os valores de arborização e área construída. Estas observações sugerem que à medida que a densidade populacional aumenta, diminui a oferta de vegetação no meio urbano.

Sendo a cidade de Arinos de pequeno porte e de baixa densidade populacional, é possível a comparação entre esta cidade e os bairros estudados em Piracicaba. A densidade demográfica apresentada para o Bairro Clube de Campo foi de 0,18 habitantes por $100 \mathrm{~m}^{2}$, a menor entre os 9 bairros estudados. A cidade de Arinos apresenta uma densidade populacional de 0,24 habitantes por $100 \mathrm{~m}^{2}$. Os resultados apresentados expressaram uma maior aproximação com os índices obtidos para o bairro Clube de Campo na cidade de Piracicaba (Tabela 2). Em Piracicaba, além do bairro Clube de Campo destacou-se positivamente os bairros Nova Piracicaba e Cidade Jardim, por apresentarem valores de Espaço Livre Vegetado (ELV) próximos do ideal preconizado por Lombardo (1985) que é de 30\% da área urbanizada coberta por vegetação arbórea, arbustiva ou herbácea. O mesmo raciocínio pode ser utilizado para a cidade de Arinos-MG que obteve 69,6\% de ELV. Tal proporção é indicada para que se obtenham adequadas condições climáticas e de qualidade de vida.

Na obtenção do Índice de Cobertura vegetal (ICV) foi feita a divisão de 10.854 habitantes 
pela área em $\mathrm{m}^{2}$ de copa de árvore que foi $1.134 .580 \mathrm{~m}^{2}$. O resultado do ICV obtido foi de aproximadamente $104 \mathrm{~m}^{2}$ por habitante. Estudo semelhante realizado por Silva, Santos e Oliveira (2016), em estudo realizado na cidade de Gurupi- TO, encontrou um ICV de 0,48 $\mathrm{m}^{2}$ de copa por habitante. Um valor de ICV menor foi encontrado em Altamira $(0,18)($ SOUZA et al., 2014). Por outro lado, Mossoró apresentou um valor de ICV de 9,57 (DE ARRUDA et al., 2013). Observase que com exceção da cidade de Mossoró, RN. As demais cidades pesquisadas carecem de um aumento substancial para atingir um melhor ICV. Ao contrário, a área urbana de Arinos-MG, tem um ICV que pode ser considerado excepcional quando comparado aos resultados encontrados na literatura, o que confirma os resultados dos demais Indicadores de Floresta Urbana. Entre os índices utilizados neste trabalho o ICV é o único que considera a população residente na área estudada, assim, o alto ICV apresentado pela cidade de Arinos, se deve em partes à sua baixa densidade populacional. Por outro lado, é inegável que a área urbana considerada continuaria a apresentar um ótimo ICV mesmo com um aumento substancial da densidade populacional.

\section{CONCLUSÕES}

O presente trabalho mostrou-se consonante com a literatura quanto a utilização de imagem espacial multiespectral para a obtenção de dados e análise da vegetação urbana, bem como sua relação com os demais componentes do espaço urbano, podendo ser uma importante ferramenta para a gestão da floresta urbana em particular e gestão do espaço público de modo geral.

Os Indicadores de Floresta Urbana, assim como seus componentes, podem ser usados para reconhecimento quantitativo da arborização urbana, além de servir como suporte na tomada de decisão quanto a melhoria da qualidade na sua distribuição, importante para que seus benefícios sejam otimizados.

A cidade de Arinos revelou um percentual de espaço livre vegetado de $69,6 \%$, o que revela um grande potencial para o incremento de sua Floresta Urbana No entanto, a inexistência de uma política de Arborização Urbana para cidades com estas características pode comprometer seriamente este potencial, pois seu crescimento, se não adequadamente planejado, tenderá ao aumento de áreas construídas, limitando a ação de agentes públicos e particulares na criação e manutenção de espaços públicos arborizados. 


\section{REFERÊNCIAS}

BARGOS, D. C.; MATIAS, L. F. Áreas verdes urbanas: um estudo de revisão e proposta conceitual. Revista da Sociedade Brasileira de Arborização Urbana, Piracicaba-SP, v. 6, n. 3, p. 172-188, 2011.

BRASIL. INSTITUTO BRASILEIRO DE GEOGRAFIA E ESTATÍSTICA. Cidades @. Censo 2014. Disponível em:<http://www.cidades.ibge.gov.br/painel/painel.php?lang=\&codmun=31 0450\&search $=\% 7 C \% 7$ Cinfogr\%E1ficos:-dados-gerais-do-munic \%E Dp io> Acesso em 7 de março de 2016.

COLTRO, E. M.; MIRANDA, G. M. Levantamento da arborização urbana pública de Irati - PR e sua influência na qualidade de vida de seus habitantes. Revista Eletrônica Lato Sensu, Curitiba-PR, Ano 2, n.1, p. 27 - 48, 2007.

COSTA, J. A.; SILVA FILHO, D.F.; POLIZEL, J.L.; Uso de imagens de alta resolução par avaliação de áreas verdes na cidade de São Paulo, Brasil. Revista da Sociedade Brasileira de Arborização Urbana. Piracicaba, SP. v.7, n.1, p. 159-181, 2012.

COSTA, R. G. S.; COLESANTI, M. M. A Contribuição da percepção ambiental nos estudos das áreas verdes. RA'E GA. Curitiba-PR, v. 22, p. 238-251, 2011.

DE ARRUDA, L. E. V.; SILVEIRA, P. R. S; VALE, H. S. M.; SILVA, P. C. M. Índice de área verde e de cobertura vegetal no perímetro urbano central do município de Mossoró, RN. Revista Verde de Agroecologia e Desenvolvimento Sustentável, Mossoró-RN, v. 8, n. 2, p. 13-17, 2013.

DUARTE, D. A. B. G.; ZIANTONIO-FILHO, V. L. Índice de área por habitante no município de Timburi/SP. In: Anais XVI Encontro Nacional dos Geógrafos. Crise, práxis e autonomia: espaços de resistência e de esperança. Espaço de diálogos e práticas. ENG, de 25 a 31 de julho, Porto Alegre - RS, 2010

LANDIS, J.R.; KOCH, G.G. The measurement of observer agreement for categorical data. The International Biometrics Society, Arlington, v.33, n.1, p.159-174, 1977.

LIMA NETO, E. M.; SOUZA, R. M. Índices de densidade e sombreamento arbóreo em áreas verdes públicas de Aracajú, Sergipe. Revista da Sociedade Brasileira de Arborização Urbana, Piracicaba-SP, v.4, n.4, p.47-62, 2009.

LOMBARDO, M. A. Iha de calor nas metrópoles: o exemplo de São Paulo. São Paulo: Editora Hucitec, 1985. 244p.

LONDE, R. P.; MENDES, P. C. A influência das áreas verdes na qualidade de vida urbana. Hygeia, Uberlândia-MG, v. 10, n. 18, p. 264-272, 2014.

LUCON, T. N.; FILHO, J. F. P.; SOBREIRA, F. G. Índice e percentual de áreas verdes para o perímetro urbano de Ouro Preto, MG. Revista da Sociedade Brasileira de Arborização Urbana, Piracicaba-SP, v. 8, n. 3, p. 63-78, 2013.

LU, D.; WENG, Q. A survey of image classification methods and techniques for improving classification performace. International Journal of Remote Sensing. London-England, v. 28, n. 5, p. 823-870, 2007. 
MARTINI, A.; BIONDI, D.; BATISTA, A. C.; ZAMPRONI, K.; VIEZZER, J.; GRISE, M. M.; NETO, E. M. L. Percepção da população sobre o conforto térmico proporcionado pela arborização de ruas de Curitiba, PR. Floresta, Curitiba-PR, v. 44, n. 3, p. 515-524, 2014.

NUCCI, J.C. Qualidade ambiental e adensamento: um estudo de planejamento da paisagem do Distrito de Santa Cecília (Município de São Paulo). 229 p. Tese (Doutorado em Geografia Física) Faculdade de Filosofia, letras e Ciências humanas, Universidade de São Paulo, 1996.

POLIZEL, J.L. Geotecnologias e clima urbano: aplicação dos recursos de sensoriamento remoto e sistema de informações geográficas na cidade de Piracicaba, SP. 153p. Tese (Doutorado em Geografia Física) - Faculdade de Filosofia, Letras e Ciências Humanas da Universidade de São Paulo, São Paulo, 2009.

PIRES, N. A. M. T.; MELO, M. S.; OLIVEIRA, D. E.; SANTOS, S. X. A arborização urbana do município de Goiandira/ GO - caracterização quali-quantitativa e propostas de manejo. Piracicaba: Revista da Sociedade Brasileira de Arborização Urbana, Piracicaba- SP, v. 5, n. 3, p. 185-205, 2010.

REIS, D. S. Avaliação do efeito de florestas urbanas e áreas vegetadas no conforto higrotérmico. 108p. Dissertação (Mestrado em Recursos Florestais) - Escola Superior de Agricultura "Luiz de Queiroz", Universidade de São Paulo, Piracicaba -SP. 2014.

RIBEIRO, J. B.; BORGO, M.; MARANHÃO, L. T. Áreas protegidas de Curitiba (PR, Brasil) como sumidouros de CO2. Floresta, Curitiba-PR, v. 43, n. 2, p. 181-190, 2013.

SHAMS, J. C. A; GIACOMELI, D. C; SUCOMINE, N. M. Emprego da Arborização na Melhoria do Conforto Térmico nos Espaços Livres Públicos. Piracicaba: Revista da Sociedade Brasileira de Arborização Urbana, Piracicaba-SP, v.4, n.4, p.1-16, 2009.

SILVA, A. D. P.; SANTOS, A. F.; OLIVEIRA, L. M. Índices de área verde e cobertura vegetal das praças públicas da cidade de Gurupi, TO. Floresta, Curitiba-PR, v. 46, n. 3, p. 353-362, 2016.

SILVA FILHO, D.F.; PIVETTA, K.F.L.; COUTO, H.T.Z.; POLIZEL, J.L. Indicadores de floresta urbana a partir de imagens aéreas multiespectrais de alta resolução. Scientia Forestalis, Piracicaba-SP, n. 67, p. 88-100, 2005.

SILVA FILHO, D.F.; MEIRA, A.M.; SETTE JUNIOR, C.R.; ALEXANDRINO, E.R.; NOGUEIRA, C.L.; GUARALDO, E.; OLIVATO, F.; ROLLO, F.M.A.; PARRA, J.; CHAGAS, M.P.; BIANCHIL, M.; GABRIEL, M.V.; CELIDONIO, R.M.G.S.; FLORSHEIN, S.M.B.; COSTA, T.J . Levantamento do potencial de arborização e proposta para três bairros no município de Piracicaba/SP, Brasil. Revista da Sociedade Brasileira de Arborização Urbana. Piracicaba-SP, v.3, n.4, p.20-39, 2008.

SILVA, I. M. Efeitos do uso e cobertura do solo sobre o conforto higrotérmico. 2012. Dissertação (Mestrado em Recursos Florestais) - Escola Superior de Agricultura Luiz de Queiroz, Universidade de São Paulo, Piracicaba, 2012.

SOUZA, O. P. S.; SOUZA, P. T. S.; FREITAS, A. D. D.; PARAENSE, V. C.; SOUZA, D. V. Indicadores de área verde e cobertura arbórea para as praças do município de Altamira, Pará. Enciclopédia Biosfera, Goiânia-GO, v. 10, n. 18, p. 1955-1962, 2014. 